\title{
Editorial: Ballroom Biology: Recent Insights into Honey Bee Waggle Dance Communications
}

\author{
Roger Schürch ${ }^{1,2 *}$, Margaret J. Couvillon ${ }^{1}$ and Madeleine Beekman ${ }^{3}$ \\ ${ }^{1}$ Laboratory of Apiculture and Social Insects, University of Sussex, Brighton, UK, ${ }^{2}$ Clinical Trials Unit, University of Bern, Bern, \\ Switzerland, ${ }^{3}$ Behaviour and Genetics of Social Insects Lab, School of Biological Sciences, University of Sydney, Sydney, \\ NSW, Australia
}

Keywords: waggle dance, honey bee, recruitment, foragers, social insects, animal communication

The Editorial on the Research Topic

Ballroom Biology: Recent Insights into Honey Bee Waggle Dance Communications

In his 1950 book Bees: Their Vison, Chemical Senses, and Language, Karl von Frisch recounts his decades of research into how honey bees perceive the world, concluding "The bee's life is like a magic well: the more you draw from it, the more it fills with water." (von Frisch, 1950). Sixty-five years on, science continues to draw from that magical well, and we have learned a tremendous amount about honey bee foraging, nest site selection and recruitment. We now understand a great deal about how the decisions made by individual bees, which usually have limited information, translate into colony-level decisions in an unpredictable environment. When studying honey bee behavior, it is impossible to ignore the role the unique waggle dance plays in the life of the bee. Honey bees use the dance to communicate the location of resources. The discovery and subsequent decoding of the waggle dance would earn Karl von Frisch a Nobel Prize in 1973.

The waggle dance is the inspiration behind the nine contributions, spanning from original experimental research to emerging methods, which we present here in this special Frontiers issue.

Scientific Research Centre of the Slovenian Academy of Sciences and Arts, Slovenia

*Correspondence: Roger Schürch roger.schuerch@ctu.unibe.ch

Specialty section:

This article was submitted to Behavioral and Evolutionary Ecology,

a section of the journal

Frontiers in Ecology and Evolution

Received: 06 November 2015 Accepted: 10 December 2015

Published: 07 January 2016

Citation:

Schürch R, Couvillon MJ and Beekman M (2016) Editorial: Ballroom

Biology: Recent Insights into Honey Bee Waggle Dance Communications.

Front. Ecol. Evol. 3:147.

doi: $10.3389 /$ fevo.2015.00147

\section{AVAILABLE INFORMATION FOR HONEY BEES}

We begin with an exploration of the information available to honey bee foragers. Rivera et al. used the duration of trophallaxis as a proxy for that individual's experience of resource quality, where a decrease in trophallaxis duration from a marked forager may suggest a decrease in forage quality. They also used forager wait time as a proxy for social information, where increased wait time for the marked returning nectar forager indicates that the colony no longer requires that resource so acutely. However, the authors did not find an effect of either on an individual bee's decision to stop foraging, reflecting that honey bee decision-making in a natural environment remains poorly understood. We do know that honey bees forage at long distances (von Frisch, 1967; Seeley, 1995). Ratnieks and Shackleton conclude that these distances, which may be up to 10-14 kilometers (Waddington et al., 1994; Beekman and Ratnieks, 2000; Couvillon et al., 2014), are exceptional, given the bee's body size. Ratnieks and Shackleton hypothesize it is the dance language that makes long distance foraging possible. The question of exactly how much information is conveyed by the waggle dance is examined directly in the contribution by Schürch and Ratnieks. By reanalyzing the information content in both vector components (direction and distance) of the dance, they demonstrate that 2.9 and 4.5 bits of information are conveyed respectively, showing that a little bit of information can go a long way if it is the right information (Schürch and Ratnieks). l'Anson Price and Grüter then review what is currently known about the circumstances that have led to 
the evolution of dance communication. They conclude that the dance information is most useful in an environment where resources are clustered, difficult to find, and of variable quality and when the environment itself is relatively stable for periods of time. Lastly, Avarguès-Weber et al. take a slightly different focus by looking not at the details conveyed from specialized signals such as the dance, but at the indirect, environmental information that bees may obtain. In doing so, they draw from work on both bees and fruit flies and discuss the evidence for observational learning and the neural circuits that may underpin it.

\section{WITHIN THE DANCE: INTRA-DANCE VARIATION AND BEE STOP SIGNALS}

Two contributions deal with specific aspects of the dance itself. Firstly, Beekman et al. examine intra-dance variation among Apis species by analyzing the dance precision of $A$. florea, A. dorsata, and $A$. mellifera in the contexts of both foraging and swarming. They find that all three species improve the precision of the dance with increasing distance to the source but that dance precision levels off. Their data supports the idea that intradance variation reflects an unavoidable constraint in the bees' ability to communicate more precisely. Kietzman and Visscher examine the bee's stop signal, which counters the waggle dance by providing negative feedback toward an advertised location. The combination of both positive feedback from the waggle dance and negative feedback from the stop signal, allows the colony to more rapidly respond to changes in the foraging environment.

\section{DANCING INTO THE FUTURE}

Lastly, two contributions look ahead toward potential research avenues that pertain to the bees' communication system. Couvillon and Ratnieks argue that the waggle dance, specifically the ability of researchers to decode the dances to determine where

\section{REFERENCES}

Beekman, M., and Ratnieks, F. L. W. (2000). Long-range foraging by the honey-bee, Apis mellifera L. Funct. Ecol. 14, 490-496. doi: 10.1046/j.13652435.2000.00443.x

Couvillon, M. J., Schürch, R., and Ratnieks, F. L. W. (2014). Waggle dance distances as integrative indicators of seasonal foraging challenges. PLoS ONE 9:e93495. doi: 10.1371/journal.pone.0093495

Seeley, T. D. (1995). The Wisdom of the Hive. Cambridge, MA: Harvard University Press.

von Frisch, K. (1923). Über die "Spräche" der Bienen, eine tier-psychologische Untersuchung Zool. Jahrb 40, 1-186.

von Frisch, K. (1950). Bees: Their Vision, Chemical Senses, and Language. Ithaca, NY: Cornell University Press.

von Frisch, K. (1967). The Dance Language and Orientation of Bees. Cambridge, MA: Harvard University Press. honey bees are foraging, may be applied as a future tool for ecology to inform on a range of ecological, conservation, and land management issues. The authors concede, however, that decoding dances by hand, which is the current methodology to extract the spatial information from the dance, is timeconsuming, an issue that may be helped by the contribution of Wario et al., where they present in their methods article the full specifications of the recording setup and the software for automatic recognition of individually tagged bees and the decoding of dances. With the development of this technology, it may be possible to track all individuals of a honey bee colony and to detect and to decode the communication dances automatically.

\section{CONCLUSION}

The diverse nature of the contributions in this special issue illustrates how, 93 years after von Frisch's first description of the honey bee's waggle dance (von Frisch, 1923), there still remains much to be learned. We hope that this eBook will continue to motivate scientists to draw from the well that is the bees' lives and further elucidate how such a tiny brain in a small insect can generate such amazingly complex behaviors as the waggle dance communication.

\section{AUTHOR CONTRIBUTIONS}

RS and MC came up with the topic idea, and MB contributed to its description and to the overall organization of the special topic. All editors contributed to the overseeing of reviews for this special issue and wrote the cover editorial.

\section{FUNDING}

MB is funded by the Australian Research Council (FT120100120 and DP140100560).

Waddington, K. D., Herbert, T. J., Visscher, P. K., and Richter, M. R. (1994). Comparisons of forager distributions from matched honey bee colonies in suburban environments. Behav. Ecol. Sociobiol. 35, 423-429. doi: 10.1007/BF00165845

Conflict of Interest Statement: The authors declare that the research was conducted in the absence of any commercial or financial relationships that could be construed as a potential conflict of interest.

Copyright (c) 2016 Schürch, Couvillon and Beekman. This is an open-access article distributed under the terms of the Creative Commons Attribution License (CC $B Y)$. The use, distribution or reproduction in other forums is permitted, provided the original author(s) or licensor are credited and that the original publication in this journal is cited, in accordance with accepted academic practice. No use, distribution or reproduction is permitted which does not comply with these terms. 